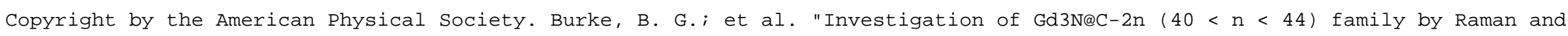

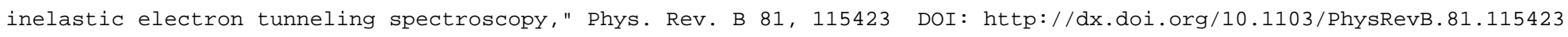

PHYSICAL REVIEW B 81, 115423 (2010)

\title{
Investigation of $\mathrm{Gd}_{3} \mathrm{~N} @ \mathrm{C}_{2 n}(40 \leq n \leq 44)$ family by Raman and inelastic electron tunneling spectroscopy
}

\author{
Brian G. Burke, Jack Chan, and Keith A. Williams* \\ Department of Physics, University of Virginia, Charlottesville, Virginia 22904, USA \\ Jiechao Ge, Chunying Shu, Wujun Fu, and Harry C. Dorn \\ Department of Chemistry, Virginia Polytechnic Institute and State University, Blacksburg, Virginia 24061, USA \\ James G. Kushmerick \\ National Institute of Standards and Technology, Gaithersburg, Maryland 20899, USA
}

\begin{abstract}
Alexander A. Puretzky and David B. Geohegan
Materials Science and Technology Division, Center for Nanophase Materials Sciences, Oak Ridge National Laboratory, Oak Ridge, Tennessee 37831, USA
\end{abstract}

(Received 30 October 2009; revised manuscript received 19 January 2010; published 15 March 2010)

\begin{abstract}
The structure and vibrational spectrum of $\mathrm{Gd}_{3} \mathrm{~N} @ \mathrm{C}_{80}$ is studied through Raman and inelastic electron tunneling spectroscopy as well as density-functional theory and universal force field calculations. Hindered rotations, shown by both theory and experiment, indicate the formation of a $\mathrm{Gd}_{3} \mathrm{~N}-\mathrm{C}_{80}$ bond which reduces the ideal icosahedral symmetry of the $\mathrm{C}_{80}$ cage. The vibrational modes involving the movement of the encapsulated species are a fingerprint of the interaction between the fullerene cage and the core complex. We present Raman data for the $\mathrm{Gd}_{3} \mathrm{~N} @ \mathrm{C}_{2 n}(40 \leq n \leq 44)$ family as well as $\mathrm{Y}_{3} \mathrm{~N} @ \mathrm{C}_{80}, \mathrm{Lu}_{3} \mathrm{~N} @ \mathrm{C}_{80}$, and $\mathrm{Y}_{3} \mathrm{~N} @ \mathrm{C}_{88}$ for comparison. Conductance measurements have been performed on $\mathrm{Gd}_{3} \mathrm{~N} @ \mathrm{C}_{80}$ and reveal a Kondo effect similar to that observed in $\mathrm{C}_{60}$.
\end{abstract}

DOI: 10.1103/PhysRevB.81.115423

PACS number(s): 78.30.Na, 33.20.Tp, 33.20.Vq

\section{INTRODUCTION}

Endohedral fullerenes (endofullerenes), due to their unique electronic and geometric structure, have been attracting the interest of chemists, physicists, and material scientists since they were first synthesized in $1985 .^{1,2}$ Potential applications include electronic devices, ${ }^{3}$ organic solar cells, ${ }^{4}$ spin-based quantum computing, ${ }^{5,6}$ and medicine, ${ }^{7-22}$ specifically contrast agents for magnetic-resonance imaging (MRI) as well as radiopharmaceutical candidates. ${ }^{8,9}$ Endofullerenes created by an arc-vaporization technique ${ }^{23}$ have been known to encapsulate clusters of the form $M_{3} \mathrm{~N}(M=\mathrm{Sc}, \mathrm{Y}$, and several lanthanides). ${ }^{2,8}$ The isolation of magnetic and radioactive $\mathrm{Gd}_{3} \mathrm{~N} @ \mathrm{C}_{2 n}$ molecules has received much interest due to their application as MRI contrast agents and the confinement of three paramagnetic $\mathrm{Gd}$ ions in a relatively small space $(\sim 1 \mathrm{~nm})$.

The vibrational modes involving the movement of the encapsulated species are a fingerprint of the interaction between the fullerene cage and the metal complex. Based on the mode frequencies, the experimental value of the metalcage bond strength can be determined and the amount of charge transfer from the cage to the core can be investigated..$^{24-26}$ It has been shown that some isolated fullerene cages, though electronically unstable, can bind strongly to the metal core and become stable. ${ }^{2,27}$ Although certain gadolinium endofullerenes have been isolated and studied by $\mathrm{x}$-ray diffraction, vibrational spectroscopy has not been performed on a number of species. 2,8

In this paper, we present a detailed Raman and inelastic electron tunneling spectroscopy (IETS) analysis of
$\mathrm{Gd}_{3} \mathrm{~N} @ \mathrm{C}_{80}$, as well as conductance measurements demonstrating a Kondo effect. Raman analysis of $\mathrm{Gd}_{3} \mathrm{~N} @ \mathrm{C}_{2 n}(40$ $\leq n \leq 44$ ) has been performed, as well as $\mathrm{Y}_{3} \mathrm{~N} @ \mathrm{C}_{80}$, $\mathrm{Lu}_{3} \mathrm{~N} @ \mathrm{C}_{80}$, and $\mathrm{Y}_{3} \mathrm{~N} @ \mathrm{C}_{88}$ for comparison. Vibrational assignments of the $\mathrm{Gd}_{3} \mathrm{~N} @ \mathrm{C}_{80}$ molecule, $I_{h}-\mathrm{C}_{80}^{6-}$ cage, and intrinsic $\mathrm{Gd}_{3} \mathrm{~N}$ cluster were carried out by density-functional theory (DFT) and universal force field (UFF) calculations. Hindered rotations, shown by both theory and experiment, indicate the formation of a $\mathrm{Gd}_{3} \mathrm{~N}-\mathrm{C}_{80}$ bond which reduces the ideal icosahedral symmetry of the $\mathrm{C}_{80}$ cage.

\section{BACKGROUND}

An isolated $\mathrm{Gd}$ atom has a large magnetic moment of $8 \mu_{B}$, where $7 \mu_{B}$ is derived from localized $f$ electrons. ${ }^{27}$ When embedded inside a fullerene, the $\mathrm{Gd}$ atom bonds through the delocalized $s$ and $d$ electrons and the localized $f$ states maintain their atomic spin moment. ${ }^{27}$ The valence state of gadolinium has been determined experimentally by electron spin resonance (ESR), X-ray photoemission spectroscopy (XPS), and x-ray diffraction to be $\mathrm{Gd}^{3+} \cdot{ }^{28-33}$ For the $\mathrm{Gd}_{3} \mathrm{~N} @ \mathrm{C}_{2 n}$ family, Gd can formally only be in the +1 charge state because with three additional electrons, one from each $\mathrm{Gd}$, the nitrogen is saturated in a formal -3 charge state. However, the highest charge state is $\mathrm{Gd}^{3+}$ and therefore the whole $\mathrm{Gd}_{3} \mathrm{~N}$ cluster can donate six electrons to the cage resulting in $\left(\mathrm{Gd}^{2+}\right)_{3} \mathrm{~N} @ \mathrm{C}_{2 n}^{6-}$. The transfer of six additional electrons stabilizes the $I_{h}-\mathrm{C}_{80}$ cage by completely filling the HOMO orbital. ${ }^{34}$

The structure of $\mathrm{Gd}_{3} \mathrm{~N} @ \mathrm{C}_{80}$ has been determined by x-ray diffraction and the $\mathrm{Gd}_{3} \mathrm{~N}$ unit is found to be pyramidal within 


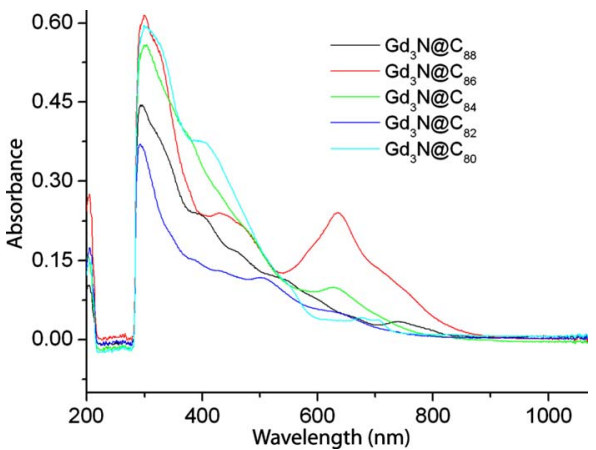

FIG. 1. (Color online) Spectrophotometry data of $\mathrm{Gd}_{3} \mathrm{~N} @ \mathrm{C}_{2 n}(40 \leq n \leq 44)$ in toluene. Unusually high absorption peak in $\mathrm{Gd}_{3} \mathrm{~N} @ \mathrm{C}_{86}$ is observed.

the $I_{h}$ cage, with the three Gd atoms positioned over the centers of hexagons. ${ }^{2,35}$ Unlike light-mass pyramidal molecules, such as $\mathrm{NH}_{3}$, the $\mathrm{N}$ atom is not able to tunnel through the $\mathrm{Gd}_{3}$ plane due to a high energy barrier. However, when the intrinsic $\operatorname{Gd}_{3} \mathrm{~N}$ molecule is encapsulated in the $\mathrm{C}_{80}$ cage the charge coupling effectively lowers the energy barrier to $\sim 91 \mathrm{meV}$, which allows tunneling to be possible. ${ }^{27}$ As the cluster has a permanent electric-dipole moment, the wagging mode involves a fluctuation in the overall dipole moment, which can be observed in the Raman spectra $\left(\sim 85 \mathrm{~cm}^{-1}\right){ }^{27}$

\section{EXPERIMENT AND RESULTS}

\section{A. Spectrophotometry and Raman measurements}

UV-Vis spectrophotometry data for $\mathrm{Gd}_{3} \mathrm{~N} @ \mathrm{C}_{2 n}(40 \leq n$ $\leq 44)$ are shown in Fig. 1. The samples were isolated by HPLC and the purity was confirmed by mass spectrometry. The endofullerenes were suspended in toluene $(99.999 \%$, Sigma-Aldrich), which was background subtracted, and plotted as a function of wavelength.

The spectral onset for $\mathrm{Gd}_{3} \mathrm{~N} @ \mathrm{C}_{80}$ is around $940 \mathrm{~nm}$. The highest occupied molecular orbital (HOMO) lowest unoccupied molecular orbital transition has a doublet structure with absorption maxima at 680 and $710 \mathrm{~nm}$. The strongest visible absorption of $\mathrm{Gd}_{3} \mathrm{~N} @ \mathrm{C}_{80}$ is at $415 \mathrm{~nm}$, and a shoulder is apparent at $555 \mathrm{~nm} .{ }^{36}$ The spectral onset for $\mathrm{Gd}_{3} \mathrm{~N} @ \mathrm{C}_{82}$ is around $950 \mathrm{~nm}$, and there are absorption peaks at 630 and $505 \mathrm{~nm}$. The spectral onset for $\mathrm{Gd}_{3} \mathrm{~N} @ \mathrm{C}_{84}$ is around $985 \mathrm{~nm}$, and there are absorption peaks at 915 and $635 \mathrm{~nm}$. The spectral onset for $\mathrm{Gd}_{3} \mathrm{~N} @ \mathrm{C}_{86}$ is around $1005 \mathrm{~nm}$, and there is an unusually strong absorption peak at $640 \mathrm{~nm}$, as well as one at $430 \mathrm{~nm}$. The spectral onset for $\mathrm{Gd}_{3} \mathrm{~N} @ \mathrm{C}_{88}$ is around $960 \mathrm{~nm}$, and there are absorption peaks at 740, 545, 460, and $405 \mathrm{~nm}$.

For spectroscopic studies, $10 \mu \mathrm{g}$ of $\mathrm{Gd}_{3} \mathrm{~N} @ \mathrm{C}_{2 n}(40 \leq n$ $\leq 44)$ were suspended in carbon disulfide $\left(\mathrm{CS}_{2}, 99.999 \%\right.$, Sigma-Aldrich) and used to dropcoat a gold-covered silicon substrate. The resulting polycrystalline films were dried under ambient conditions and placed in a Linkam liquidnitrogen cryostat stage. Raman spectra were studied with $632.8 \mathrm{~nm}$ excitation from a HeNe laser. The scattered light was collected in the backscattering geometry by a triple-axis spectrometer (Jobin Yvon Horiba, T64000) equipped with a charge-coupled device detector. A resolution of $0.7 \mathrm{~cm}^{-1}$
(1800 gr/mm) was used for all Raman measurements and all measurements used $2.5 \mathrm{~mW} / \mathrm{cm}^{2}$ laser power, $30 \mathrm{~min}$ accumulation time, and were performed at $90 \mathrm{~K}$.

The Raman spectra observed for $\mathrm{Gd}_{3} \mathrm{~N} @ \mathrm{C}_{80}$ can be roughly divided into four parts: tangential $\mathrm{C}_{80}$ modes are found between 1000 and $1600 \mathrm{~cm}^{-1}$, a gaplike region from 815 to $1000 \mathrm{~cm}^{-1}$, radial $\mathrm{C}_{80}$ modes between 200 and $815 \mathrm{~cm}^{-1}$, and a fourth group from $200 \mathrm{~cm}^{-1}$ and below which has a counterpart only in the spectra of endohedral and polymeric fullerenes which exhibit low energetic $\mathrm{Gd}$ cage, intermolecular, and center-of-mass (COM) modes. Low-energy Raman modes of $\mathrm{Gd}_{3} \mathrm{~N} @ \mathrm{C}_{80}$ have been observed confirming the coupling between the core and cage by hindered rotation modes (Fig. 2).

Several prominent modes can be identified such as the $\mathrm{C}_{80} \mathrm{H}_{g}(1)$ squashing mode at $234 \mathrm{~cm}^{-1}$, the $\mathrm{H}_{g}(2)$ twist mode at $361 \mathrm{~cm}^{-1}$, and the $A_{g}(1)$ breathing mode at $430 \mathrm{~cm}^{-1}$. Below $200 \mathrm{~cm}^{-1}$, several peaks are observed indicating a hindered rotation due to the bonding of $\mathrm{Gd}_{3} \mathrm{~N}$ to the $\mathrm{C}_{80}$ cage. Other groups have seen evidence for the formation of a $M_{3} \mathrm{~N}-\mathrm{C}_{80}$ bond which induces a significant reduction of the ideal $I_{h}-\mathrm{C}_{80}$ symmetry. ${ }^{2,37,38}$ A peak at $83.6 \mathrm{~cm}^{-1}$ appears to be the wagging mode of the nitrogen atom through the $\mathrm{Gd}_{3}$ plane, predicted by theory. ${ }^{27}$ Other $\mathrm{COM}$ modes are identified, where the cage-core complex translates relative to the other. The frequencies of these peaks were compared with the other gadolinium endofullerenes and are listed in Table I.

A similar procedure was performed to analyze the vibrational spectrum of the $\mathrm{Gd}_{3} \mathrm{~N} @ \mathrm{C}_{2 n}(41 \leq n \leq 44)$ family. It can be clearly seen that the low-energy Raman modes are changed as the number of cage atoms increases (Fig. 3). A common mode for all samples arising from the coupling of the motion of the Gd complex and the fullerene cage seems to be apparent. The mode, defined from $140-165 \mathrm{~cm}^{-1}$ and identified boldly in Table I, can be assigned to the Gd-cage stretching mode. The $165 \mathrm{~cm}^{-1}$ mode for $\mathrm{Gd}_{3} \mathrm{~N} @ \mathrm{C}_{80}$ compares well with previous experimental results. ${ }^{2,36,38}$ This particular mode is similar to the vibrational mode reported for $\mathrm{Gd} @ \mathrm{C}_{82}$, which exhibits a Raman frequency at $155 \mathrm{~cm}^{-1} \cdot 2,24$

When plotting this mode against the square root of the reciprocal reduced mass, $\left[1 / m_{\text {reduced }}\left(\mathrm{Gd}_{3} \mathrm{~N}-\mathrm{C}_{2 n}\right)\right]^{1 / 2}$, a linear trend is found (Fig. 4). As the carbon cage mass increases, a linear frequency downshift is observed due to a decrease in the bond strength between the core complex and the cage. It is interesting to note that previous x-ray data have distinguished $\mathrm{Gd}_{3} \mathrm{~N} @ \mathrm{C}_{80}$, which obeys the IPR and contains a pyramidal $\mathrm{Gd}_{3} \mathrm{~N}$ unit, from $\mathrm{Gd}_{3} \mathrm{~N} @ \mathrm{C}_{82}$ and $\mathrm{Gd}_{3} \mathrm{~N} @ \mathrm{C}_{84}$ which contain planar $\mathrm{Gd}_{3}$ units and carbon cages that do not follow the IPR. ${ }^{2,8}$ Although no X-ray or NMR data has been conducted for $\mathrm{Gd}_{3} \mathrm{~N} @ \mathrm{C}_{86}$ and $\mathrm{Gd}_{3} \mathrm{~N} @ \mathrm{C}_{88}$, the cages most likely follow the IPR and have $D_{3}$ and $D_{2}$ symmetry, respectively. ${ }^{39,40}$ It is important to note that unlike $\mathrm{Gd}_{3} \mathrm{~N} @ \mathrm{C}_{80}$, which has a preference for icosahedral symmetry $\left(I_{h}\right)$, the other molecules have several IPR isomers that could be present in the Raman data.

Raman data of $\mathrm{Y}_{3} \mathrm{~N} @ \mathrm{C}_{80}$ and $\mathrm{Lu}_{3} \mathrm{~N} @ \mathrm{C}_{80}$ were analyzed in order to compare with the gadolinium complex $\mathrm{Gd}_{3} \mathrm{~N} @ \mathrm{C}_{80}$ (Fig. 5). There is agreement above $220 \mathrm{~cm}^{-1}$, 


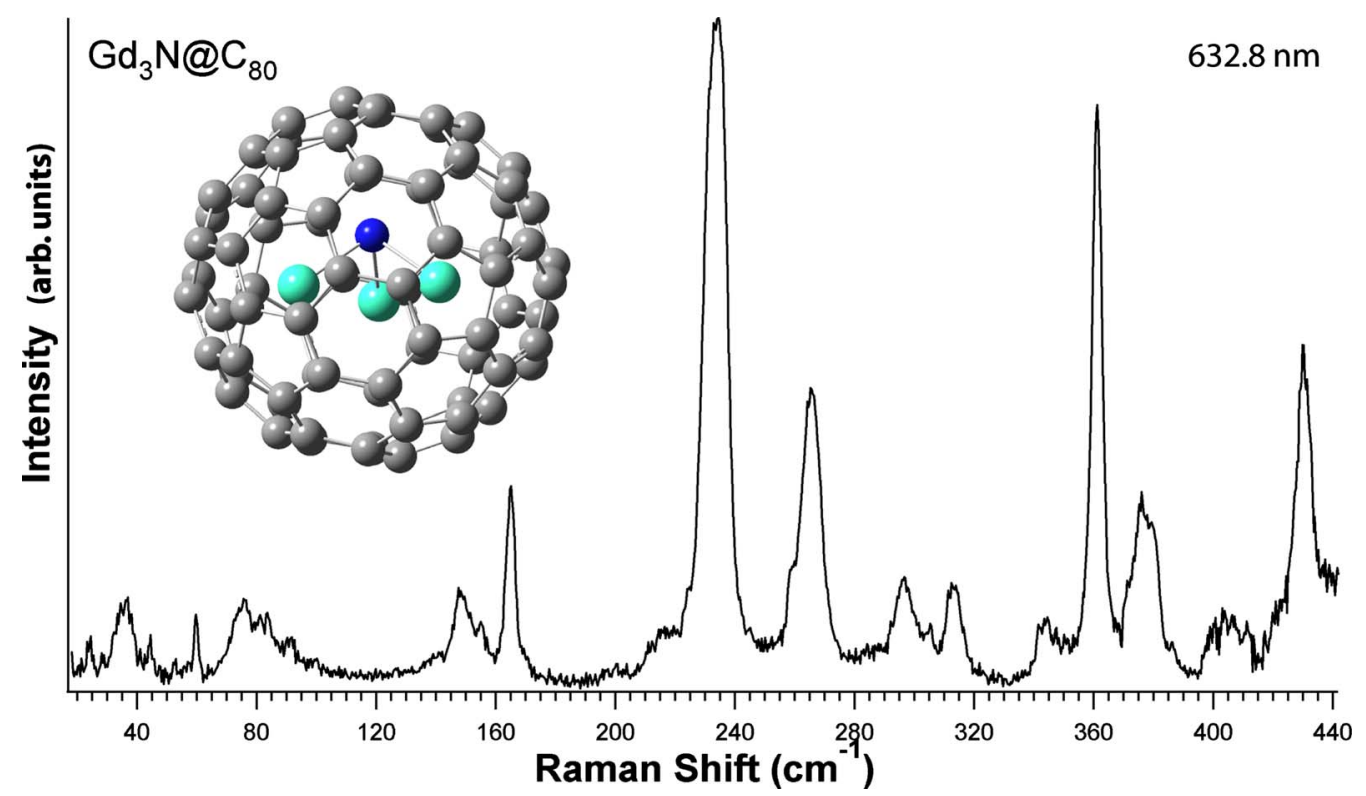

FIG. 2. (Color online) Analysis of low-energy Raman lines of $\mathrm{Gd}_{3} \mathrm{~N} @ \mathrm{C}_{80}$ taken at $90 \mathrm{~K}$ indicating a hindered rotation due to the coupling of the core complex to the cage. Inset gives the $\mathrm{Gd}_{3} \mathrm{~N} @ \mathrm{C}_{80}$ structure.

which identifies the $\mathrm{C}_{80}$ cage modes. The frequency of the $M$-cage stretching mode is increased to $195.6 \mathrm{~cm}^{-1}$ for the yttrium complex, ${ }^{2,38}$ due to the change in reduced mass (32.7\% decrease), and decreased to $155.9 \mathrm{~cm}^{-1}$ for the lutetium complex, due to the change in reduced mass $(7.0 \%$ increase). Assuming harmonic motion, a force constant $k$ $=12.8 \pm 0.37 \mathrm{~N} / \mathrm{cm}$ can be derived, and it can be concluded that the frequency shift of the $M_{3} \mathrm{~N}-\mathrm{C}_{80}$ oscillator is solely due to the change in metal mass. ${ }^{41} \mathrm{~A}$ splitting and separation of the M-cage stretching modes $\left(123.4-195.6 \mathrm{~cm}^{-1}\right)$ is observed as the metal mass increases from yttrium to lutetium, as well as COM modes below $120 \mathrm{~cm}^{-1}$.

Raman data of $\mathrm{Y}_{3} \mathrm{~N} @ \mathrm{C}_{88}$ has also been studied in order to compare with $\mathrm{Gd}_{3} \mathrm{~N} @ \mathrm{C}_{88}$ (Fig. 6). There is excellent agreement above $250 \mathrm{~cm}^{-1}$, despite several possible isomers, which identifies the $\mathrm{C}_{88}$ cage modes. The frequency of the

TABLE I. Low-energy Raman frequencies $\left(\mathrm{cm}^{-1}\right)$ of $\mathrm{Gd}_{3} \mathrm{~N} @ \mathrm{C}_{2 n}(40 \leq n \leq 44)$ below $200 \mathrm{~cm}^{-1}$ at $90 \mathrm{~K}$. Bold frequencies represent the Gd-cage stretching mode, which appears to be common for all gadolinium samples.

\begin{tabular}{ccccc}
\hline \hline $\mathrm{Gd}_{3} \mathrm{~N} @ \mathrm{C}_{80}$ & $\mathrm{Gd}_{3} \mathrm{~N} @ \mathrm{C}_{82}$ & $\mathrm{Gd}_{3} \mathrm{~N} @ \mathrm{C}_{84}$ & $\mathrm{Gd}_{3} \mathrm{~N} @ \mathrm{C}_{86}$ & $\mathrm{Gd}_{3} \mathrm{~N} @ \mathrm{C}_{88}$ \\
\hline $\mathbf{1 6 5 . 2}$ & 165.9 & 176.0 & $\mathbf{1 4 5 . 7}$ & 194.3 \\
148.4 & $\mathbf{1 5 5 . 4}$ & 156.2 & 106.9 & 152.8 \\
91.5 & 137.5 & $\mathbf{1 5 0 . 8}$ & 90.7 & $\mathbf{1 4 1 . 9}$ \\
83.6 & 111.2 & 115.5 & 83.2 & 91.9 \\
74.9 & 95.5 & 110.4 & 74.9 & 86.8 \\
59.8 & 59.4 & 95.1 & 59.4 & 76.2 \\
44.6 & 51.4 & 74.1 & 51.4 & 60.7 \\
35.8 & 27.4 & 60.2 & 43.5 & 51.9 \\
24.2 & & 44.6 & 35.8 & 43.9 \\
& & 35.8 & 27.0 & 36.3 \\
& & 28.6 & 19.8 & 28.3 \\
\hline \hline
\end{tabular}

M-cage stretching mode is increased to $171.8 \mathrm{~cm}^{-1}$ for the yttrium complex, due to the change in reduced mass $(33.3 \%$ decrease). Assuming harmonic motion, a force constant $k$ $=9.9 \pm 0.12 \mathrm{~N} / \mathrm{cm}$ can be derived and one can conclude that the frequency shift of the $M_{3} \mathrm{~N}-\mathrm{C}_{88}$ oscillator is solely due to the change in metal mass. ${ }^{41}$ Several COM modes are observed in $\mathrm{Gd}_{3} \mathrm{~N} @ \mathrm{C}_{88}$ at $93.5,74.5,60.2,43.9$, and $21.4 \mathrm{~cm}^{-1}$, respectively.

\section{B. IETS and conductance measurements}

The low-temperature charge transport properties of $\mathrm{Gd}_{3} \mathrm{~N} @ \mathrm{C}_{80}$ junctions were measured in a crossed-wire apparatus. ${ }^{42} \mathrm{~A} \mathrm{Gd}_{3} \mathrm{~N} @ \mathrm{C}_{80}$ layer is deposited from a $\sim 10 \mathrm{pM} \mathrm{CS}_{2}$ solution onto a $10-\mu \mathrm{m}$-diameter $\mathrm{Au}$ wire and mounted into a custom-built cryostat. A second

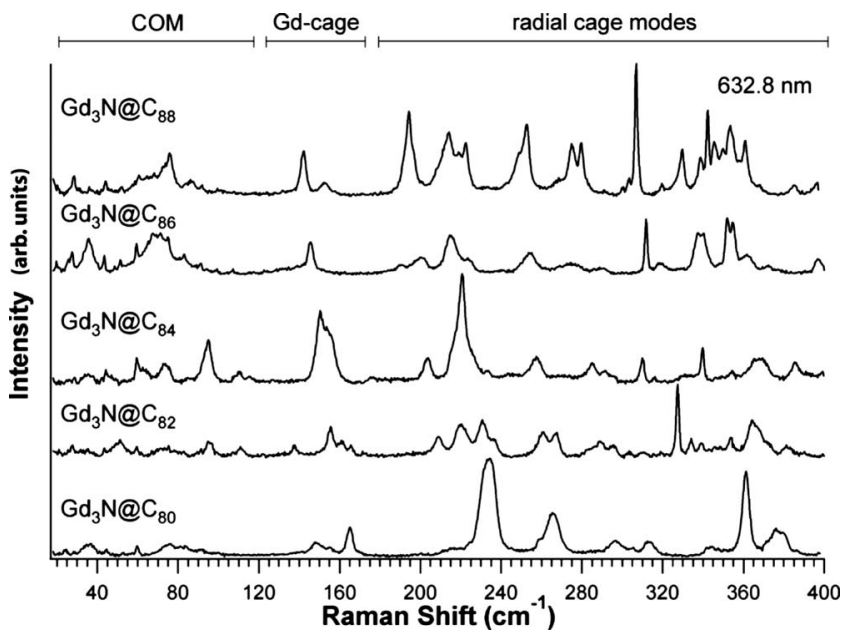

FIG. 3. Analysis of low-energy Raman lines of $\mathrm{Gd}_{3} \mathrm{~N} @ \mathrm{C}_{2 n}(40 \leq n \leq 44)$ taken at $90 \mathrm{~K}$ indicating a hindered rotation due to the coupling of the core complex to the cage. 


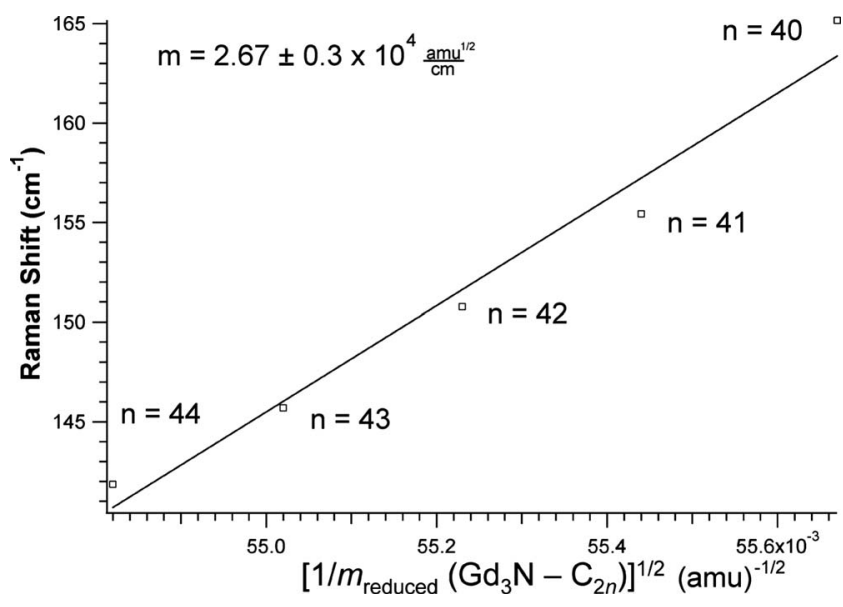

FIG. 4. Analysis of Gd-cage stretching mode plotted against the square root of the reciprocal reduced mass. As the carbon mass increases, there is a linear downshift in the frequency.

$10-\mu \mathrm{m}$-diameter $\mathrm{Au}$ wire serves as the top electrode. The cryostat assembly is evacuated, back filled with helium gas, and submerged into a liquid-helium storage dewar. The junctions were formed after thermal equilibrium was reached and all transport measurements were performed at a temperature of $4.2 \mathrm{~K}$. Due to the nature of tunneling spectra, cryogenic temperatures are necessary to obtain good resolution and no additional temperature ranges were studied. In Fig. 7, a zerobias conductance peak commonly associated with Kondo scattering $^{43}$ is clearly present.

The Kondo effect is a many-body phenomenon that can arise from the coupling between a localized spin (Anderson impurity) and a sea of conduction electrons. It has been shown that molecules composed of magnetic ions can have a nonzero magnetic moment and give rise to Kondo scattering. ${ }^{44-46}$ The magnetic moment of the gadolinium ions is due to the localized $4 f$ states, which exhibit a nonvanishing magnetic moment and a localized single spin. The interaction of the $f$ electrons from the three $\mathrm{Gd}^{2+}$ ions within the $\mathrm{C}_{80}$ cage may in principle lead to the observed Kondo effect.

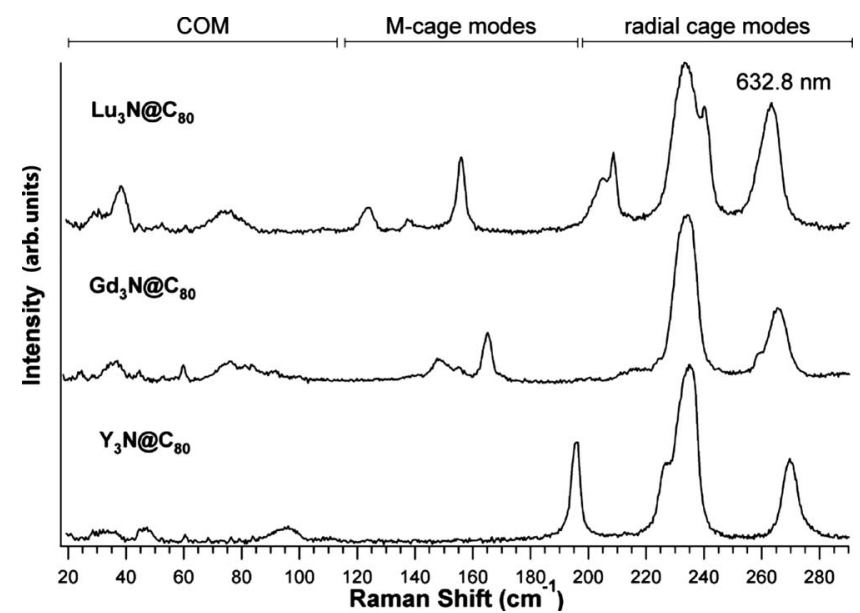

FIG. 5. Comparison of $\mathrm{Y}_{3} \mathrm{~N} @ \mathrm{C}_{80}, \mathrm{Gd}_{3} \mathrm{~N} @ \mathrm{C}_{80}$, and $\mathrm{Lu}_{3} \mathrm{~N} @ \mathrm{C}_{80}$ low-energy Raman data taken at $90 \mathrm{~K}$. Analysis of the data identifies $\mathrm{C}_{80}$ cage modes, hindered rotation modes, and center-of-mass modes.

Following the Fano model, ${ }^{44}$ the zero-bias peak can be fitted and gives the values $q=0.031 \pm 0.004, \Gamma=13.1 \pm 0.3 \mathrm{meV}$, and $\alpha=-0.2 \pm 0.1 \mathrm{meV}$ (Fig. 7, inset). From these values, a Kondo temperature $\mathrm{T}_{K} \sim 76 \mathrm{~K}$ can be determined.

It is important to note however, that similar Kondo scattering has been previously observed for junctions containing $\mathrm{C}_{60}$ that do not have an intrinsic magnetic moment. ${ }^{47,48}$ Therefore, it is difficult to identify if the spin impurity is due to the $\mathrm{C}_{80}$ cage, the gadolinium complex, or some combination of the two. Further investigation by magnetic scanning tunneling microscopy (STM) or spin-polarized low-energy electron microscopy (SPLEEM) is required to have a more detailed analysis of the system.

Satellite peaks in the conductance data at $\pm 42 \mathrm{mV}\left(339 \mathrm{~cm}^{-1}\right)$, similar to those reported ${ }^{48}$ for $\mathrm{C}_{60}$ at $\pm 33 \mathrm{mV}\left(266 \mathrm{~cm}^{-1}\right)$, are also observed in the conductance spectra of the $\mathrm{Gd}_{3} \mathrm{~N} @ \mathrm{C}_{80}$ junction. However, unlike previous groups who identified the peaks as the $\mathrm{H}_{g}(1)$ squashing mode for $\mathrm{C}_{60}$, the observed satellite peaks cannot be definitively

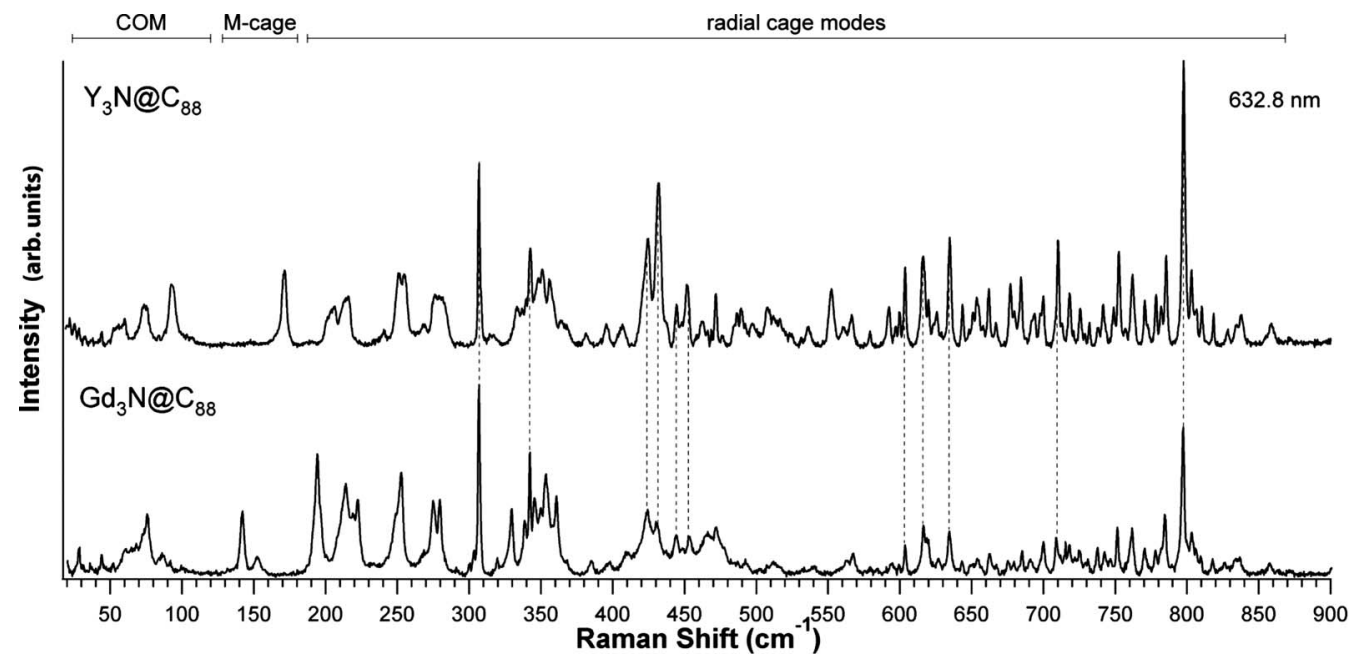

FIG. 6. Comparison of $\mathrm{Y}_{3} \mathrm{~N} @ \mathrm{C}_{88}$ and $\mathrm{Gd}_{3} \mathrm{~N} @ \mathrm{C}_{88}$ Raman data taken at $90 \mathrm{~K}$. Analysis of the data identifies $\mathrm{C}_{88}$ cage modes, hindered rotation modes and center-of-mass modes. Prominent peak correlations are denoted by dotted lines. 


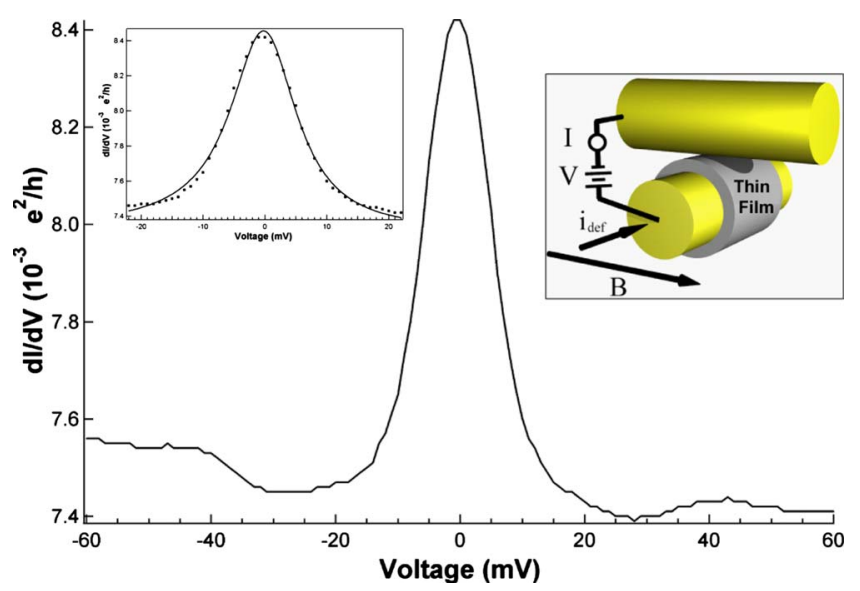

FIG. 7. (Color online) Experimental conductance data of Kondo effect and zero-bias anomaly in $\mathrm{Gd}_{3} \mathrm{~N} @ \mathrm{C}_{80}$ taken at $4.2 \mathrm{~K}$. Right inset adapted from Ref. 42 shows the experimental setup: $\mathrm{Au}$ crossed-wire apparatus forms a junction with the $\mathrm{Gd}_{3} \mathrm{~N} @ \mathrm{C}_{80}$ thin film. Left inset shows the calculated fit (solid line) using the Fano model.

correlated with any intramolecular modes of $\mathrm{Gd}_{3} \mathrm{~N} @ \mathrm{C}_{80}$.

Not all junctions formed exhibited the Kondo signature shown in Fig. 7. In fact, the transport properties were more or less evenly split between the Kondo resonance previously discussed and more conventional nonresonant tunneling and inelastic electron tunneling signatures. ${ }^{49}$ The inelastic electron tunneling spectrum of a $\mathrm{Gd}_{3} \mathrm{~N} @ \mathrm{C}_{80}$ junction is shown in Fig. 8. There is a strong line at $81.6 \mathrm{mV}\left(658 \mathrm{~cm}^{-1}\right)$ which has been identified previously by IR spectroscopy as the antisymmetric Gd-N stretching vibration of the $\mathrm{Gd}_{3} \mathrm{~N}$ cluster. ${ }^{2,36,38}$ Raman $\mathrm{C}_{80}$ cage modes are also observed at 155.1 (1251) and $187.5 \mathrm{mV}\left(1512 \mathrm{~cm}^{-1}\right)$. The vibrational spectrum obtained by IETS is complimentary to Raman and IR measurements since although there are no strong selection rules ${ }^{50,51}$ the molecular vibrations observed provides insight into the conduction pathways through the molecular species. $^{52}$

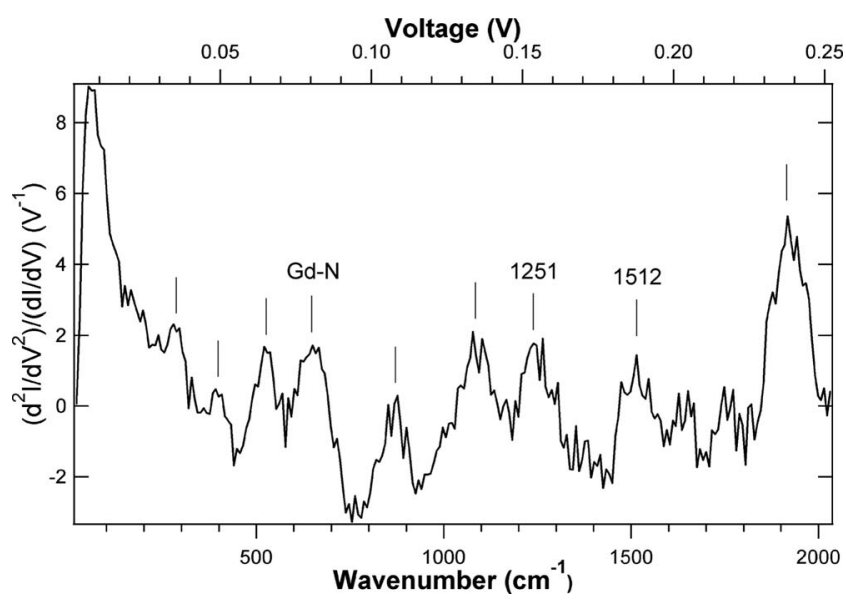

FIG. 8. Experimental IETS spectrum obtained for $\mathrm{Gd}_{3} \mathrm{~N} @ \mathrm{C}_{80}$ with modulation amplitude $\mathrm{V}_{\omega}=4 \mathrm{mV}$, scan rate $=1.5 \mathrm{mV} / \mathrm{s}$, and time constant=1 s. The antisymmetric Gd-N stretch mode is identified at $81.6 \mathrm{mV}\left(658 \mathrm{~cm}^{-1}\right)$ as well as Raman $\mathrm{C}_{80}$ cage modes at $155.1(1251)$ and $187.5 \mathrm{mV}\left(1512 \mathrm{~cm}^{-1}\right)$.
TABLE II. Experimental and theoretical Raman frequencies $\left(\mathrm{cm}^{-1}\right)$ for $\mathrm{Gd}_{3} \mathrm{~N} @ \mathrm{C}_{80}, I_{h}-\mathrm{C}_{80}^{6-}$, and intrinsic $\mathrm{Gd}_{3} \mathrm{~N}$.

\begin{tabular}{ccc}
\hline \hline $\mathrm{Gd}_{3} \mathrm{~N} @ \mathrm{C}_{80}(\mathrm{Exp})$ & $\mathrm{Gd}_{3} \mathrm{~N} @ \mathrm{C}_{80}(\mathrm{UFF})$ & $I_{h}-\mathrm{C}_{80}^{6-}(\mathrm{DFT})$ \\
\hline $430.4 A_{g}(1)$ & $428.5 A_{g}(1)$ & $429.7 A_{g}(1)$ \\
376.1 & 372.1 & 375.6 \\
$361.3 \mathrm{H}_{g}(2)$ & $370.7 \mathrm{H}_{g}(2)$ & $355.3 \mathrm{H}_{g}(2)$ \\
343.1 & 356.3 & 302.4 \\
313.2 & 302.2 & 298.1 \\
296.4 & 255.9 & $227.2 \mathrm{H}_{g}(1)$ \\
265.7 & 229.1 & \\
$234.5 \mathrm{H}_{g}(1)$ & $217.9 \mathrm{H}_{g}(1)$ & \\
$165.2 \mathrm{Gd}$ cage & $141.8 \mathrm{Gd} \mathrm{cage}$ & \\
148.4 & 116.3 & $\mathrm{Gd}_{3} \mathrm{~N}(\mathrm{UFF})$ \\
91.5 & 115.4 & 747.8 \\
83.6 & 84.2 & 511.5 \\
74.9 & 79.2 & 112.1 \\
59.8 & 75.5 & 94.8 \\
44.6 & 46.7 & \\
35.8 & 44.3 & \\
24.2 & 25.4 & \\
\hline \hline
\end{tabular}

\section{DFT and UFF calculations}

In the case of $\mathrm{C}_{80}$, its 12 pentagonal and 30 hexagonal faces can be arranged in seven different structures consistent with the IPR. ${ }^{53}$ The $\mathrm{C}_{80}$ cage has elicited significant interest in part because after $\mathrm{C}_{60}$, it has the smallest fullerene cage with an icosahedral isomer. Due to the icosahedral symmetry of the cage most of the vibrational modes are highly degenerate and fall into 62 distinct mode frequencies. The intramolecular modes can be analyzed and classified according to their symmetry ${ }^{54}$ and from group theory it follows that 14 of the modes are Raman active $\left(3 A_{g}\right.$ and $\left.11 \mathrm{H}_{g}\right), 6$ are IR active $\left(\mathrm{F}_{1 u}\right)$, and the remaining 42 are optically silent. Vibrational modes for the isolated $I_{h}-\mathrm{C}_{80}^{6-}$ cage were calculated by hybrid DFT (B3LYP) utilizing the STO-3G/3-21G basis sets in the GAUSSIAN 03 package. ${ }^{55}$ The results were compared with experimental $\mathrm{Gd}_{3} \mathrm{~N} @ \mathrm{C}_{80}$ cage modes in Table II. Pure $\mathrm{C}_{80}$ cage vibrations should not be affected by the mass of the endohedral atoms. ${ }^{37}$

The $\mathrm{C}_{80}^{6-}$ model accounts only for the charge transfer in endohedral complexes, which is a very simplified approximation of the core-cage interaction. In reality, the electronic properties of endofullerenes are determined additionally by the hybridization of the core-cage orbitals. Describing the presence of gadolinium only by adding electrons to the cage neglects some important effects arising from Gd-cage chemical bonding. In such a simple model the extra electrons are delocalized over the whole molecule, whereas more complex calculations for the endofullerenes predict localization of the charge in the vicinity of the chemisorption site.

DFT calculations of $\mathrm{Gd}_{3} \mathrm{~N} @ \mathrm{C}_{80}$ could not be carried out due to several delocalized electrons in the $d$ and $f$ orbitals of gadolinium. Therefore, UFF calculations of $\mathrm{Gd}_{3} \mathrm{~N} @ \mathrm{C}_{80}$ and $\mathrm{Gd}_{3} \mathrm{~N}$ were conducted and compared with both experimental 
values of $\mathrm{Gd}_{3} \mathrm{~N} @ \mathrm{C}_{80}$ and DFT calculations of $I_{h}-\mathrm{C}_{80}^{6-}$ in Table II. The UFF calculated Gd-cage mode at $141.8 \mathrm{~cm}^{-1}$ compares well with previous theoretical calculations. ${ }^{38}$

The intrinsic $\mathrm{Gd}_{3} \mathrm{~N}$ molecule has six vibrational modes, two of which are degenerate. One mode with $A_{1}$ symmetry is a breathing mode or Gd-N symmetric stretch, where the $\mathrm{Gd}$ triangle expands and contracts. For the $A_{1}$ wagging mode or out-of-plane breathing mode, the $\mathrm{Gd}_{3}$ moiety and the central nitrogen atom are displaced from the molecular plane in opposite directions. One of the $E$ modes is a doubly degenerate in-plane mode or asymmetric Gd-N stretching mode. The other $E$ mode is an out-of-plane normal vibration or scissor mode, which involves changes in the Gd-N-Gd bond angle. All normal-mode vibrations of the free $\mathrm{Gd}_{3} \mathrm{~N}$ molecule are both Raman and IR active.

The normal modes of the free $\mathrm{Gd}_{3} \mathrm{~N}$ molecule have been calculated by UFF. The doubly degenerate scissor mode or $\delta$ (Gd-N-Gd) and asymmetric stretch or $\nu_{\text {as }}(\mathrm{Gd}-\mathrm{N})$ have values at 94.8 and $747.8 \mathrm{~cm}^{-1}$, respectively. The wagging mode or $\gamma\left(\mathrm{Gd}_{3}-\mathrm{N}\right)$ has the value of $511.5 \mathrm{~cm}^{-1}$, whereas the breathing mode or $\nu_{s}(\mathrm{Gd}-\mathrm{N})$ has a value of $112.1 \mathrm{~cm}^{-1}$. The wagging mode is related to a Raman vibrational mode of $\mathrm{GdN}$ at $530 \mathrm{~cm}^{-1}$ reported previously. ${ }^{56}$

\section{CONCLUSIONS}

We have described the structure and vibrational spectrum of the $\mathrm{Gd}_{3} \mathrm{~N} @ \mathrm{C}_{2 n}(40 \leq n \leq 44)$ family. The endofullerenes were characterized by Raman spectroscopy, IETS, UV-Vis spectrophotometry, and molecular modeling (DFT and UFF).
Tangential and radial cage modes, low-energy Gd-cage modes, intermolecular modes, and COM modes were identified in the Raman spectra. Hindered rotations were observed experimentally and calculated theoretically, indicating the formation of a $\mathrm{Gd}_{3} \mathrm{~N}-\mathrm{C}_{2 n}(40 \leq n \leq 44)$ bond which reduces the symmetry of the cage. As the carbon cage mass increases, a linear frequency downshift of the hindered rotation modes is observed due to a decrease in the bond strength between the core and the cage. Raman studies were conducted on $\mathrm{Y}_{3} \mathrm{~N} @ \mathrm{C}_{80}, \mathrm{Lu}_{3} \mathrm{~N} @ \mathrm{C}_{80}$, and $\mathrm{Y}_{3} \mathrm{~N} @ \mathrm{C}_{88}$ for comparison with the $\mathrm{Gd}_{3} \mathrm{~N} @ \mathrm{C}_{2 n}$ family. $\mathrm{Gd}_{3} \mathrm{~N} @ \mathrm{C}_{80}$ was further investigated by conductance measurements in a crosswire apparatus at low temperature. A zero-bias conductance peak associated with Kondo scattering was observed. Based on these observations, we suggest that it is possible to utilize magnetic endofullerenes in magnetoelectronic device applications, while characterizing the molecules through Raman, IETS, and microscopy.

\section{ACKNOWLEDGMENTS}

The authors thank Smitha Vasudevan for her assistance with molecular modeling. We are grateful for support of this work by the National Science Foundation [Grants No. CHE0443850 (H.C.D.) and No. DMR-0507083 (H.C.D.)] and the National Institutes of Health [Grant No. 1R01-CA119371-01 (H.C.D.)]. A portion of this research at Oak Ridge National Laboratory's Center for Nanophase Materials Science was sponsored by the Scientific User Facilities Division, Office of Basic Energy Sciences, U.S. Department of Energy.
*Corresponding author; kwilliams@virginia.edu

${ }^{1}$ J. Heath, S. C. O'Brien, Q. Zhang, Y. Liu, R. F. Curl, F. K. Tittel, and R. E. Smalley, J. Am. Chem. Soc. 107, 7779 (1985).

${ }^{2}$ A. A. Popov, J. Comput. Theor. Nanosci. 6, 292 (2009).

${ }^{3}$ S. Kobayashi, S. Mori, S. Iida, H. Ando, T. Takenobu, Y. Taguchi, A. Fujiwara, A. Taninaka, H. Shinohara, and Y. Iwasa, J. Am. Chem. Soc. 125, 8116 (2003).

${ }^{4}$ R. B. Ross, C. M. Cardona, D. M. Guldi, S. G. Sankaranarayanan, M. O. Reese, N. Kipipdakis, J. Peet, B. Walker, G. C. Bazan, E. Van Keuren, B. C. Holloway, and M. Drees, Nature Mater. 8, 208 (2009).

${ }^{5}$ W. Harneit, Phys. Rev. A 65, 032322 (2002).

${ }^{6}$ J. A. Larsson, J. C. Greer, W. Harneit, and A. Weidinger, J. Chem. Phys. 116, 7849 (2002).

${ }^{7}$ H. Kato, Y. Kanazawa, M. Okumura, A. Taninaka, T. Yokawa, and H. Shinohara, J. Am. Chem. Soc. 125, 4391 (2003).

${ }^{8}$ H. Yang, C. Lu, Z. Liu, H. Jin, Y. Che, M. M. Olmstead, and A. L. Balch, J. Am. Chem. Soc. 130, 17296 (2008).

${ }^{9}$ T. Zuo, L. Xu, C. M. Beavers, M. M. Olmstead, W. Fu, T. D. Crawford, A. L. Balch, and H. C. Dorn, J. Am. Chem. Soc. 130, 12992 (2008).

${ }^{10}$ S. R. Zhang, D. Y. Sun, X. Y. Li, F. K. Pei, and S. Y. Liu, Fullerene Sci. Technol. 5, 1635 (1997).

${ }^{11}$ L. J. Wilson, D. W. Cagle, T. P. Thrash, S. J. Kennel, S. Mirzadeh, J. M. Alford, and G. J. Ehrhardt, Coord. Chem. Rev. 190-
192, 199 (1999)

${ }^{12}$ L. J. Wilson, The Electrochemical Society Interface, Winter (1999), Vol, 24.

${ }^{13}$ M. Mikawa, H. Kato, M. Okumura, M. Narataki, Y. Kanazawa, N. Miwa, and H. Shinohara, Bioconjugate Chem. 12, 510 (2001).

${ }^{14}$ E. B. Iezzi, J. C. Duchamp, K. R. Fletcher, T. E. Glass, and H. C. Dorn, Nano Lett. 2, 1187 (2002).

${ }^{15}$ M. Okumura, M. Mikawa, T. Yokawa, Y. Kanazawa, H. Kato, and H. Shinohara, Acad. Radiol. 9, S495 (2002).

${ }^{16}$ R. D. Bolskar, A. F. Benedetto, L. O. Husebo, R. E. Price, E. F. Jackson, S. Wallace, L. J. Wilson, and J. M. Alford, J. Am. Chem. Soc. 125, 5471 (2003).

${ }^{17}$ P. P. Fatouros, F. D. Corwin, Z. J. Chen, W. C. Broaddus, J. L. Tatum, B. Kettenmann, Z. Ge, H. W. Gibson, J. L. Russ, A. P. Leonard, J. C. Duchamp, and H. C. Dorn, Radiology 240, 756 (2006).

${ }^{18}$ E. Zhang, C. Shu, L. Feng, and C. Wang, J. Phys. Chem. B 111, 14223 (2007).

${ }^{19}$ B. Sitharaman and L. J. Wilson, Journal of Biomedical Nanotechnology 3, 342 (2007).

${ }^{20}$ M. N. Chaur, F. Melin, A. J. Athans, B. Elliott, K. Walker, B. C. Holloway, and L. Echegoyen, Chem. Commun. (Cambridge) (2008) 2665.

${ }^{21}$ C. Shu, C. Wang, J. Zhang, H. W. Gibson, H. C. Dorn, F. D. 
Corwin, P. P. Fatouros, and T. J. S. Dennis, Chem. Mater. 20, 2106 (2008)

${ }^{22}$ C. Shu, X. Ma, J. Zhang, F. D. Corwin, J. H. Sim, E. Y. Zhang, H. C. Dorn, H. W. Gibson, P. P. Fatouros, C. R. Wang, and X. H. Fang, Bioconjugate Chem. 19, 651 (2008).

${ }^{23}$ S. Stevenson, G. Rice, T. Glass, K. Harich, F. Cromer, M. R. Jordan, J. Craft, E. Hajdu, R. Bible, M. M. Olmstead, K. Maitra, A. J. Fisher, A. L. Balch, and H. C. Dorn, Nature (London) 401, 55 (1999).

${ }^{24}$ S. Lebedkin, B. Renker, R. Heid, H. Schober, and H. Rietschel, Appl. Phys. A: Mater. Sci. Process. 66, 273 (1998).

${ }^{25}$ R. Jaffiol, A. Débarre, C. Julien, D. Nutarelli, P. Tchénio, A. Taninaka, B. Cao, T. Okazaki, and H. Shinohara, Phys. Rev. B 68, 014105 (2003).

${ }^{26}$ M. Krause, M. Hulman, H. Kuzmany, P. Kuran, L. Dunsch, T. J. S. Dennis, M. Inakuma, and H. Shinohara, J. Mol. Struct. 521, 325 (2000).

${ }^{27}$ M. Qian, S. V. Ong, S. N. Khanna, and M. B. Knickelbein, Phys. Rev. B 75, 104424 (2007).

${ }^{28}$ H. Shinohara, Rep. Prog. Phys. 63, 843 (2000).

${ }^{29}$ K. Shibata, Y. Rikiishi, T. Hosokawa, Y. Haruyama, Y. Kubozono, S. Kashino, T. Uruga, A. Fujiwara, H. Kitagawa, T. Takano, and Y. Iwasa, Phys. Rev. B 68, 094104 (2003).

${ }^{30}$ L. Moro, R. S. Ruoff, C. H. Becker, D. C. Lorents, and R. Malhotra, J. Phys. Chem. 97, 6801 (1993).

${ }^{31}$ H. Funasaka, K. Sugiyama, K. Yamamoto, and T. Takahashi, J. Phys. Chem. 99, 1826 (1995).

${ }^{32}$ K. Laasonen, W. Andreoni, and M. Parrinello, Science 258, 1916 (1992)

${ }^{33}$ J. Ding, L. Weng, and S. Yang, J. Phys. Chem. 100, 11120 (1996).

${ }^{34}$ K. Kobayashi and S. Nagase, Chem. Phys. Lett. 262, 227 (1996).

${ }^{35}$ J. Lu, R. F. Sabirianov, W. N. Mei, Y. Gao, C. Duan, and X. Zeng, J. Phys. Chem. B 110, 23637 (2006).

${ }^{36}$ M. Krause and L. Dunsch, Angew. Chem., Int. Ed. 44, 1557 (2005).

${ }^{37}$ M. Krause, H. Kuzmany, P. Georgi, L. Dunsch, K. Vietze, and G. Seifert, J. Chem. Phys. 115, 6596 (2001).

${ }^{38}$ S. Yang, S. I. Troyanov, A. A. Popov, M. Krause, and L. Dunsch,
J. Am. Chem. Soc. 128, 16733 (2006).

${ }^{39}$ T. Zuo, C. M. Beavers, J. C. Duchamp, A. Campbell, H. C. Dorn, M. M. Olmstead, and A. L. Balch, J. Am. Chem. Soc. 129, 2035 (2007).

${ }^{40}$ W. J. Fu, L. S. Xu, H. Azurmendi, J. C. Ge, T. Furher, T. M. Zuo, J. Reid, C. Y. Shu, K. Harich, and H. C. Dorn, J. Am. Chem. Soc. 131, 11762 (2009).

${ }^{41}$ M. Krause, X. Liu, J. Wong, T. Pichler, M. Knupfer, and L. Dunsch, J. Phys. Chem. A 109, 7088 (2005).

${ }^{42}$ J. G. Kushmerick, J. Lazorcik, C. H. Patterson, R. Shashidhar, D. S. Seferos, and G. C. Bazan, Nano Lett. 4, 639 (2004).

${ }^{43}$ J. Kondo, Prog. Theor. Phys. 32, 37 (1964).

${ }^{44}$ A. Zhao, Q. Li, L. Chen, H. Xiang, W. Wang, S. Pan, B. Wang, X. Xiao, J. Yang, J. G. Hou, and Q. Zhu, Science 309, 1542 (2005).

${ }^{45}$ P. Wahl, L. Diekhöner, G. Wittich, L. Vitali, M. A. Schneider, and K. Kern, Phys. Rev. Lett. 95, 166601 (2005).

${ }^{46}$ V. Iancu, A. Deshpande, and S. Hla, Nano Lett. 6, 820 (2006).

${ }^{47}$ L. Yu and D. Natelson, Nano Lett. 4, 79 (2004).

${ }^{48}$ J. J. Parks, A. R. Champagne, G. R. Hutchison, S. Flores-Torres, H. D. Abruña, and D. C. Ralph, Phys. Rev. Lett. 99, 026601 (2007).

${ }^{49}$ R. Jaklevic and R. C. Lambe, Phys. Rev. Lett. 17, 1139 (1966).

${ }^{50}$ P. K. Hansma, Tunneling Spectroscopy: Capabilities, Applications, and New Techniques (Plenum, New York, 1982).

${ }^{51}$ J. M. Beebe, H. J. Moore, T. R. Lee, and J. G. Kushmerick, Nano Lett. 7, 1364 (2007).

${ }^{52}$ A. Troisi, J. M. Beebe, L. B. Picraux, R. D. Van Zee, D. R. Stewart, M. A. Ratner, and J. G. Kushmerick, Proc. Natl. Acad. Sci. U.S.A. 104, 14255 (2007).

${ }^{53}$ P. W. Fowler and D. E. Monolopoulos, An Atlas of Fullerenes (Oxford University Press, Oxford, 1995).

${ }^{54}$ M. S. Dresselhaus, G. Dresselhaus, and P. C. Eklund, Science of Fullerenes and Carbon Nanotubes (Academic, San Diego, 1996).

${ }^{55}$ M. J. Frisch et al., GAUSSIAN 03, Revision C.02 (Gaussian Inc., Willingford, CT, 2004).

${ }^{56}$ S. Granville, C. Meyer, A. R. H. Preston, B. M. Ludbrook, B. J. Ruck, H. J. Trodahl, T. R. Paudel, and W. R. L. Lambrecht, Phys. Rev. B 79, 054301 (2009). 